\title{
The use of dextrose in winemaking
}

\author{
Matthias Schmitt ${ }^{\mathrm{a}}$ and Monika Christmann \\ Hochschule Geisenheim, University von Lade Straße 1, 65366 Geisenheim, Germany
}

\begin{abstract}
In this work the benefit of using dextrose instead of sucrose was investigated. Trials with stuck fermentation could show the potential of compensating glucose / fructose imbalances by adding dextrose. Trials on sparkling wine production showed that under stressful conditions the second fermentation started earlier and finished more complete, when dextrose was used instead of sucrose in the tirage liqueur. In general the sensory property of the later product was not changed when dextrose was used as alternative to sucrose. Several trials on must chaptalization showed in general no clear differences in terms of fermentation kinetics. The aroma analysis showed as well, that the fermentation aroma was not clearly different when dextrose used as sugar source.
\end{abstract}

\section{Introduction}

Alcohol increase is a common practice in many winemaking countries worldwide. Either the addition of sugar in form of sucrose, must concentrate or rectified must concentrate is applied or subtractive methods that concentrate the must are used to increase the potential alcohol content. In sparkling wine production, the second fermentation is most commonly facilitated by the targeted addition of sugar and yeast. The so called tirage liqueur is used in enology worldwide.

Approximately $10 \%$ of the global wine production is influenced by stuck and sluggish fermentation (Gafner 2012). That means the yeast (mainly saccharomyces cerevisiae or bayanus strains) is not fermenting the sugar completely.

Low quality wines and significant financial losses often result from incomplete fermentations. Residual sugar is often a source for spoilage microorganisms that generate products which have a negative effect on wine quality (e.g. acetic acid/volatile acidity). This spoilage can range from small sensory defects to complete loss of the wine where it cannot be marketed anymore. Furthermore, some products, such as premium red wines, should not have residual sugar.

The misbalance in the fructose/glucose ratio is a primarily reason for fermentation problems (Gafner 2012). In a normal must, fructose and glucose are present in similar ratio. During fermentation glucose is metabolized more efficiently by the yeast compared to fructose (Bertels et al. 2004). Especially in stressful conditions i.e. lack of nutrients, high alcohol contents (end of fermentation) or high pressure (during sparkling wine production), the fermentation of dextrose instead of fructose is more efficient. At the last part of the fermentation, when the stress on the yeast is very high, there is mainly fructose left.

The addition of dextrose could help to overcome fermentation problems due to imbalances in the fructose/glucose ratio. By adding dextrose the fructose/glucose

a e-mail: Matthias.Schmitt@hs-gm.de ratio becomes more balanced and the yeast's vitality might rise again.

For the production of sparkling wine a complete fermentation is necessary to reach the targeted pressure. Low nutrient supply and high alcohol content in combination with high pressure make the second fermentation very stressful and a complete fermentation is not ensured.

The common strategies to solve fermentation problems are very costly and labor intensive (Bisson 1999). A restart of a stuck fermentation by adding new and more robust yeast cultures is time consuming and harms the later wine quality and a complete fermentation is still not guaranteed.

The use of very robust yeast is also a hazard for other wines that should not undergo a complete fermentation. These cultures often have higher $\mathrm{SO}_{2}$ tolerances. New strains that are selected for their ability to ferment better under high fructose levels, such as Zygosaccharomyces bailii, show elevated resistance towards preservatives to avoid unwanted fermentations. As the wine industry is generally forced to reduce sulfur dosages, it should not be an option to use these very robust yeasts. The spoilage of a wine that should have residual sugar by such very robust strains is a very realistic scenario. In that case, a recall of bottled wine is the worst possible case. All winemakers worldwide would prefer a gentle, easy and safe method curing stuck fermentations, before severe problems might occur.

\section{Material and methods}

Since 2014 several trials have been conducted at the Hochschule Geisenheim University to assess the potential of dextrose being used in enology.

The trials concerning stuck and sluggish fermentation had a setup comparing four different variants. Different wines with residual sugar mainly consisting of fructose were inoculated by different yeast cultures. In the first trial variant a robust yeast strain (Vitileuvre DV 10 / Lallemand, Montréal, Canada) was added in a dosage of $30 \mathrm{~g} / \mathrm{hl}$. In comparison to that the second trial variant 
Chart 1. Trial overview 2014.

\begin{tabular}{|c|c|c|c|}
\hline Sample & Initial Alcohol content & Free sulfur & Sugar source \\
\hline 1 & $13.3 \%$ vol. & $15 \mathrm{mg} / \mathrm{l}$ & Sucrose \\
\hline 2 & $13.3 \%$ vol. & $30 \mathrm{mg} / \mathrm{l}$ & Sucrose \\
\hline 3 & $13.3 \%$ vol. & $15 \mathrm{mg} / \mathrm{l}$ & Dextrose \\
\hline 4 & $13.3 \%$ vol. & $30 \mathrm{mg} / \mathrm{l}$ & Dextrose \\
\hline 5 & $11.8 \%$ vol. & $15 \mathrm{mg} / \mathrm{l}$ & Sucrose \\
\hline 6 & $11.8 \%$ vol. & $30 \mathrm{mg} / 1$ & Sucrose \\
\hline 7 & $11.8 \%$ vol. & $15 \mathrm{mg} / 1$ & Dextrose \\
\hline 8 & $11.8 \%$ vol. & $30 \mathrm{mg} / 1$ & Dextrose \\
\hline
\end{tabular}

was inoculated by a fructophilic yeast strain (Lalvin W33 / Lallemand, Montréal, Canada) The third variant was combining a robust yeast strain (Vitileuvre DV 10 / Lallemand, Montréal, Canada) with the addition of dextrose in the same amount of the present fructose. Due to that, the fructose/glucose ratio was balanced again to finish the fermentation with new yeast. The fourth trial variant was a modification from the variant 3 . Here the yeast was put for three days in a medium with dextrose as the only sugar source. Then the yeast starter was added to the wine to finish the fermentation.

The trials with sparkling wine fermentation were done according to the traditional bottle fermentation.

In 2014 the trials were done with varying stress factors. The initial base wine was a 2012 Pinot Blanc.

As shown in chart 1 the alcohol level was $13.3 \%$ vol. in the first 4 variants. The variants 5-8 had a reduced alcohol content. Here the initial base wine was treated by osmotic distillation to reduce the alcohol level under the same parameters as explained in Schmitt et al. 2014.

The trials in 2015 were conducted with base wines that had more common and suitable parameters for sparkling wine production. Two Rieslings with $12.6 \%$ vol. each and a Pinot Noir with 12,1\% vol. were used for the sparkling wine trials.

To test the suitability of dextrose compared to sucrose, the tirage liqueur was containing either $24 \mathrm{~g} / \mathrm{l}$ of dextrose or sucrose. Furthermore the tirage liqueur was containing:

$30 \mathrm{~g} / \mathrm{hl}$ Vitileuvre DV 10 (Lallemand, Montréal, Canada).

Phosphaté compose $5 \mathrm{~g} / \mathrm{hl}$ (Oenotechnic de Champagne, Magenta, France).

Sekt Clar Plus (Erbslöh, Geisenheim, Germany).

Vitadrive F3 (Erbslöh, Geisenheim, Germany).

The base wine was homogenized with the tirage liqueur and was bottled. Each lot contained 40 bottles that were closed by crown caps. The fermentation intensity in terms of pressure increase was monitored by aphrometers. Furthermore, a sugar analysis was done once a week.

After nine months of storage, the riddling was carried out. The disgorging was performed by hand. The lees were frozen before in a cooling bath at $-30^{\circ} \mathrm{C}$. To homogenize the lot, the bottles were emptied in a keg, $70 \mathrm{mg} / \mathrm{l}$ of $\mathrm{SO}_{2}$ was added and the pressure was adjusted to six bar. After 3 days the homogenized sparkling wine was bottled under counter pressure and closed by crown caps.
Chart 2. Tasting 2014 Sparkling Wine Trial.

\begin{tabular}{|l|l|l|l|c|}
\hline Test & $\begin{array}{l}\text { Without } \\
\text { answer }\end{array}$ & $\begin{array}{l}\text { Answers } \\
\text { take }\end{array}$ & $\begin{array}{l}\text { Answers } \\
\text { right }\end{array}$ & $\begin{array}{c}\text { Significance } \\
\text { (Risk) }\end{array}$ \\
\hline Sample 5 / 7 & 2 & 11 & 6 & 0.1221 \\
\hline Sample 5 / 7 & 2 & 11 & 0 & $>0.9999$ \\
\hline Sample 6 / 8 & 2 & 11 & 9 & $0.0014^{* *}$ \\
\hline Sample 6 / 8 & 2 & 11 & 7 & $0.0386^{*}$ \\
\hline
\end{tabular}

The chaptalization trials were conducted with fermenting must. The must was clarified by settling for 18 hours and $40 \mathrm{mg} / 1$ of $\mathrm{SO}_{2}$ were added. Furthermore a pasteurisation was conducted for 20 seconds at $82^{\circ} \mathrm{C}$. Then the must was cooled to $15^{\circ} \mathrm{C}$ and the fermentation was started by adding $30 \mathrm{~g} / \mathrm{hl}$ of yeast (Oenoferm Freddo / Erbslöh, Geisenheim, Germany). The fermentation intensity was supervised by temperature, density and cell number.

The analysis of the basic wine parameters were done by WineScan $\mathrm{SO}_{2}$ (Foss, Hillerod, Denmark).

Several triangle tests were conducted according to ISO 4120:2004 and ISO 8589:1988 (iso.org) to check if there is a significant difference between the control and the two wines treated in different scenarios (chart 2).

Aroma analyses were conducted to evaluate if there is a change in fermentation aromas due to a differing sugar sources. The analysis were done by the Insitute of microbiology and biochemistry of the Hochschule Geisenheim University according to Rapp et al. (1994) modified by Fischer and Rauhut.

\section{Results and discussion}

The trials concerning stuck fermentations showed similar fermentation results for all samples. The robust yeast, the fructophilic yeast and the variants with balanced glucose/fructose ratio fermented to dryness without clear differences.

The sparkling wine trials in 2014 showed that the fermentation under stressful conditions in terms of high sulfur and alcohol levels started earlier and was more complete when dextrose was used instead of sucrose in the tirage liqueur. The trials in 2015 confirmed these results. The start of the fermentation appeared, like in 2014, earlier, the pressure increase was faster and the fermentation was more complete when dextrose was utilized instead of sucrose.

The sparkling wines from the 2014 trials were also assessed by sensory evaluation. As the trials with the high alcohol levels did not all complete fermentation a complete sensory evaluation could not be done due to differences in residual sugar. The variants with moderate alcohol contents were assessed by triangle tests.

The dextrose and sucrose samples with moderate alcohol and sulfur levels showed a clear significance. Nevertheless, none of the samples was clearly preferred by the panelists. The variants 6 and 8 could not be differed from each other by the panelists. A final ranking test of the samples $5-8$ showed no significant difference in the panelist's preference. 
Chart 3. Aroma Analysis Chaptalization trials.

\begin{tabular}{|c|c|c|c|c|c|c|c|c|c|c|}
\hline Sample & $\begin{array}{c}\text { Pinot } \\
\text { Blanc } \\
\text { Sucrose }\end{array}$ & $\begin{array}{c}\text { Pinot } \\
\text { Blanc } \\
\text { Dextrose }\end{array}$ & $\Delta$ in $\%$ & $\begin{array}{l}\text { Riesling } \\
\text { Sucrose }\end{array}$ & $\begin{array}{l}\text { Riesling } \\
\text { Dextrose }\end{array}$ & $\Delta$ in $\%$ & $\begin{array}{c}\text { Rosé } \\
\text { Sucrose }\end{array}$ & $\begin{array}{c}\text { Rosé } \\
\text { Dextrose }\end{array}$ & $\Delta$ in $\%$ & \\
\hline i-Butanol (mg/L) & 26 & 21 & -27.78 & 42 & 39 & -9.79 & 34 & 38 & 11.71 & \\
\hline Isopentyl alcohol (mg/l) & 105 & 96 & -8.99 & 123 & 117 & -4.73 & 131 & 112 & -16.67 & \\
\hline 2-methylbutanol (mg/l) & 29 & 27 & -4.53 & 34 & 29 & -16.66 & 38 & 30 & -27.67 & \\
\hline Hexanol $(\mu \mathrm{g} / \mathrm{l})$ & 1041 & 1652 & 36.99 & 762 & 634 & -20.14 & 956 & 711 & -34.42 & \\
\hline Phenylethyl Alcohol (mg/l) & 12 & 15 & 16.85 & 15 & 14 & -13.18 & 21 & 15 & -36.00 & \\
\hline Ethyl acetate (mg/l) & 70 & 54 & -29.16 & 80 & 59 & -35.15 & 75 & 71 & -6.29 & \\
\hline Ethyl propionate $(\mu \mathrm{g} / \mathrm{l})$ & 69 & 62 & -12.15 & 119 & 107 & -10.54 & 108 & 110 & 2.14 & \\
\hline Ethyl butyrate $(\mu \mathrm{g} / \mathrm{l})$ & 400 & 345 & -16.07 & 437 & 419 & -4.44 & 378 & 441 & 14.33 & \\
\hline Ethyl L-lactate (mg/l) & 23 & 9 & -147.32 & 14 & 13 & -11.12 & 12 & 14 & 10.93 & $\begin{array}{l}<25 \mathrm{mg} / \mathrm{L} \\
\text { outside the } \\
\text { calibration }\end{array}$ \\
\hline Isoamyl acetate $(\mu \mathrm{g} / \mathrm{l})$ & 1666 & 1302 & -27.94 & 1538 & 1803 & 14.72 & 2696 & 3023 & 10.84 & $\begin{array}{l}>2500 \mu \mathrm{g} / \mathrm{L} \\
\text { outside the } \\
\text { calibration }\end{array}$ \\
\hline 2-Methylbuylacetate ( $\mu \mathrm{g} / \mathrm{l})$ & 113 & 104 & -7.97 & 102 & 114 & 10.39 & 232 & 258 & 10.14 & $\begin{array}{l}>250 \mu \mathrm{g} / \mathrm{L} \\
\text { outside the } \\
\text { calibration }\end{array}$ \\
\hline Ethyl hexanoate ( $\mu \mathrm{g} / \mathrm{l})$ & 1282 & 1189 & -7.78 & 917 & 1033 & 11.31 & 875 & 959 & 8.83 & \\
\hline Hexyl acetate $(\mu \mathrm{g} / \mathrm{l})$ & 372 & 329 & -13.13 & 176 & 215 & 18.26 & 308 & 321 & 4.11 & \\
\hline Diethyl succinate $(\mu \mathrm{g} / \mathrm{l})$ & 102 & 48 & -114.22 & 151 & 91 & -65.91 & 13 & 11 & -11.28 & \\
\hline Caprylic acid ethyl ester $(\mu \mathrm{g} / \mathrm{l})$ & 1643 & 1518 & -8.24 & 1220 & 1418 & 13.96 & 1310 & 1481 & 11.53 & $\begin{array}{l}>1500 \mu \mathrm{g} / \mathrm{L} \\
\text { outside the } \\
\text { calibration }\end{array}$ \\
\hline Alpha-Terpineol ( $\mu \mathrm{g} / \mathrm{l})$ & nd & nd & & 18 & 18 & -1.58 & nd & nd & & \\
\hline Ethyl phenylacetate $(\mu \mathrm{g} / \mathrm{l})$ & nd & nd & & nd & nd & & nd & nd & & \\
\hline Phenethyl acetate $(\mu \mathrm{g} / \mathrm{l})$ & 155 & 134 & -15.92 & 134 & 149 & 10.17 & 321 & 316 & -1.58 & \\
\hline Ethyl decanoate $(\mu \mathrm{g} / \mathrm{l})$ & 605 & 599 & -1.06 & 455 & 603 & 24.52 & 627 & 699 & 10.29 & $\begin{array}{l}>550 \mu \mathrm{g} / \mathrm{L} \\
\text { outside the } \\
\text { calibration }\end{array}$ \\
\hline Hexanoic acid (mg/l) & 10 & 10 & -0.82 & 8 & 8 & 1.92 & 8 & 7 & -4.97 & \\
\hline Octanoic acid (mg/l) & 10 & 9 & -12.94 & 9 & 9 & 3.67 & 7 & 8 & 8.39 & $\begin{array}{l}>10 \mathrm{mg} / \mathrm{L} \\
\text { outside the } \\
\text { calibration }\end{array}$ \\
\hline Decanoic acid (mg/l) & 3.5 & 3.3 & -6.10 & 2.8 & 3.3 & 15.36 & 2.7 & 3.2 & 14.29 & \\
\hline trans Linalool oxide $(\mu \mathrm{g} / \mathrm{l})$ & nd & nd & & 8 & 8 & -4.70 & nd & nd & & $\begin{array}{l}<10 \mu \mathrm{g} / \mathrm{L} \\
\text { outside the } \\
\text { calibration }\end{array}$ \\
\hline Cis Linalool oxide $(\mu \mathrm{g} / \mathrm{l})$ & nd & nd & & 3 & 3 & -14.12 & nd & nd & & $\begin{array}{l}<10 \mu \mathrm{g} / \mathrm{L} \\
\text { outside the } \\
\text { calibration }\end{array}$ \\
\hline Linalool $(\mu \mathrm{g} / \mathrm{l})$ & 3 & 3 & 7.00 & 25 & 26 & 3.04 & 4 & 4 & -8.51 & $\begin{array}{l}<10 \mu \mathrm{g} / \mathrm{L} \\
\text { outside the } \\
\text { calibration }\end{array}$ \\
\hline
\end{tabular}


In 2015 no significant difference could be found between the samples fermented with sucrose and dextrose. That was the case for both Riesling sparkling wines and the Pinot Noir sparkling wine.

The chaptalization trials showed in 2014 and 2015 similar fermentation kinetics. The samples were dextrose was applied did not differ in terms of sugar reduction and fermentation temperature from the samples were sucrose was used. There was only one exception in 2014. In that case all samples from the Pinot Blanc got stuck and did not finish the fermentation completely. Here the samples that were chaptalized with dextrose could ferment further than the samples where sucrose was used. The tasting of the chaptalized wines showed no significant difference between the particular trial pairs.

The aroma analyses showed that there was no severe change of the fermentation aroma when dextrose was used instead of sucrose. In general, there were no clear differences between the samples were dextrose was used instead of sucrose. These measurements confirm the results of the sensory tests

\section{Conclusion}

The use of dextrose in enology shows great potential to solve or avoid stuck and sluggish fermentations. Especially under stressful conditions like sparkling wine fermentation, dextrose is a senseful alternative to sucrose. The fermentation starts earlier and under extreme conditions, the fermentation is more complete when dextrose is used instead of sucrose.

The sensory analysis showed no clear significant difference between dextrose and sucrose being used for chaptalization or for tirage liqueur. The aroma analysis could confirm that, as the fermentation aroma generally was not affected by dextrose as sucrose alternative.

\section{References}

[1] M. Schmitt, M. Murgo, S. Prieto, Does osmotic distillation change the isotopic relation of wines?, $37^{\text {th }}$ world congress of vine and wine, Mendoza, Argentina (2014)

[2] Berthels, N.J., Cordero Otero, R.R., Bauer, F.F., Thevelein, J.M., Pretorius, I.S. (2004) Discrepancy in glucose and fructose utilization during fermentation by Saccharomyces cerevisiae wine yeast strains, FEMS yeast research, 4, 683-689

[3] Bisson, L.F. (1999) Stuck and Sluggish Fermentations, American Journal of Enology and Viticulture, 50, 107-119

[4] Gafner, J. (2012) Der Einsatz fructophiler Weinhefen zum Verhindern und Kurieren von Gärstockungen, 13. Fachsymposium Lebensmittemikrobiologie, Hohenheim, Germany 